\title{
Challenges for the Implementation of the Renewable Heat Incentive - An Example from a School Refurbishment Geothermal Scheme
}

\author{
Ross Donaldson ${ }^{\mathrm{a}, *}$, Richard Lord ${ }^{\mathrm{b}}$ \\ ${ }^{a}$ Department of Civil and Environmental Engineering, University of Strathclyde, Glasgow, Scotland, United Kingdom \\ ${ }^{\mathrm{b}}$ Department of Civil and Environmental Engineering, University of Strathclyde, Glasgow, Scotland, United Kingdom
}

\section{Highlights}

- The Renewable Heat Incentive (RHI) aims to incentivise renewable heat uptake across the UK.

- A school geothermal refurbishment project adopts heat pumps, made viable because of the RHI payments.

- Initial analysis shows that on site issues, such as planning and installation reveals awareness of the $\mathrm{RHI}$ and metering is lacking during the construction phase, compromising project viability.

\begin{abstract}
The Government run UK Renewable Heat Incentive (RHI) scheme allows cash back payments to be made to producers of renewable heat. As a world first for renewable heat, it aims to tackle head on the issues surrounding emissions, energy use, and climate change targets. However, whilst the scheme goes a long way towards meeting these climate change targets, issues have been identified that may compromise its effectiveness. This paper aims to examine the progress of the RHI since its launch in November 2011, and avenues towards a more effective deployment.
\end{abstract}

\section{Keywords}

Renewable Heat Incentive

Ground Source Heat Pumps

Geothermal

\subsection{Introduction}

Renewable energy and the link to climate change targets is a discussion that today tops the bill across many sectors. The UK Government has a legally binding target of achieving $15 \%$ of its energy consumption through renewable means by $2020^{[1]}$, as well as reducing greenhouse gas emissions by $34 \%$ on 1990 levels $^{[2]}$.

Unfortunately, interim targets so far have not been met - for example, the previous UK Government's target of reducing carbon dioxide emissions by $20 \%$ by 2010 was not achieved ${ }^{[3]}$ which makes meeting 2020 targets across EU Climate Change policies particularly challenging. A cost effective and efficient balance between economic and industrial growth, whilst

* Corresponding author at: Department of Civil and Environmental Engineering, University of Strathclyde, Glasgow, Scotland, United Kingdom. Tel: +44 7830444711.

E-mail addresses: ross.donaldson@strath.ac.uk (Ross Donaldson), richard.lord@strath.ac.uk (Richard Lord). 
incorporating a reduction in greenhouse gas emissions, must soon be developed; that is, a transition to a low carbon economy.

\subsection{Carbon Reduction}

For carbon dioxide, the greenhouse gas that is most notably attributed as the main human driver behind climate change, the European Commission (EC) is recommending that emissions on 1990 levels be reduced by $25 \%$ by 2020 , and $40 \%$ by 2030 , to make the transition to a low carbon economy cost efficient ${ }^{[4]}$. Taking the UK's groundwork on interim 2010 targets into account, a lot has to be done in this area to make these EC figures a reality.

As of 2010 , the UK Government has managed to reduce their own carbon emissions by $14 \%$, however carbon emissions as a whole for the UK grew for the year 2010, then reduced for $2011^{[5]}$. Linked to the recession, the economy showed a moderate recovery for 2010 followed by the recession taking hold again in 2011. This recent downturn in the economy is a good development for reducing carbon emissions, but in the long term provides no certainty for securing a definite reduction in carbon emissions on 1990 levels.

\section{$1.2 \quad$ Heating}

Of the UK energy usage mix, heating is the single biggest sector in terms of energy consumption, with heating and electricity together forming the biggest sector in terms of carbon emissions ${ }^{[6]}$. As electricity and heating are so closely linked - that is, we use in part electricity to heat our homes, offices, and industrial spaces, and likewise use electricity to cool them - an approach that considers heating as a critical mass within the energy debate should therefore net a twofold win in meeting climate change targets as we move towards 2020.

\subsection{Incentive Schemes}

Feed-In Tariffs (FITs) are already commonplace, where domestic and industrial producers of renewable electricity are paid in part for the electricity that they produce, even if they use it themselves ${ }^{[7]}$. Other Government programmes such as the Carbon Emissions Reduction Target (CERT) and the Community Energy Saving Programme (CESP) aim to incentivise energy efficiency, reduce carbon emissions, and tackle fuel poverty, and have so far proven to be highly successful in development within these areas ${ }^{[8]}$.

By measuring energy produced instead of electricity fed in, heat can also be produced inline with a scheme such as the $\mathrm{FITs}^{[9]}$. It is clear that considering heat within this framework is critical in order to see successful improvements in a sector that requires significant reform if it is to be aligned with emissions targets and the future UK energy portfolio.

\subsection{The Renewable Heat Incentive}

FITs were introduced as part of the Energy Act (2008) and at the same time a provision was also made to allow the Secretary of State to establish a financial support programme for renewable heat - this is known as the Renewable Heat Incentive (RHI) scheme ${ }^{[10]}$. 
A world first for renewable heat generation, the Government run $\mathrm{RHI}$ scheme aims to tackle head on the issues surrounding the reduction of carbon emissions and meeting climate change targets by incentivising the uptake of renewable heat across the UK. Open to non-domestic applications in December 2011, with the domestic regime to follow in spring 2014, the scheme allows cash back payments to be made to producers of renewable heat, where heat is derived from technologies including solid biomass, ground and water source heat pumps, solar thermal, solid biomass in Municipal Solid Waste (MSW), biogas and biomethane injection ${ }^{[11]}$. Ultimately, the $\mathrm{RHI}$ is aiming to provide a maximum rate of return of $12 \%$ on the additional capital costs of installing the renewables to combat investor hurdles ${ }^{[12]}$. This varies by technology, for example in the case of solar thermal where the rate of return is $6 \%{ }^{[13]}$, mirroring installation and deployment costs associated with the specified technology.

The RHI largely has the potential to generate the returns on investment that are required to make many projects viable with payback periods that are satisfactory ${ }^{[14]}$.

\subsection{Policy and Process}

Policy and regulations concerning the $\mathrm{RHI}$ are managed by the Department of Energy and Climate Change (DECC), with administration for the scheme being handled by the Office of Gas and Electricity Markets (Ofgem) ${ }^{[11]}$. This builds on Ofgem's successful achievements such as that for the administration for the FITs.

The process of applying for the $\mathrm{RHI}$ is two fold. Firstly, the applicant must be the owner of the installation (as defined as eligible by Ofgem), and the installation must be installed prior to the application being submitted ${ }^{[11]}$. The application is submitted online via Ofgem's website, and is to include details of the installation, commissioning certificates, as well as schematic diagrams. Ofgem will then accredit the installation or enquire further about the nature of the project if clarification is required. If approved, quarterly heat readings are submitted online by the applicant and quarterly payments are received accordingly inline with the $\mathrm{RHI}$ tariffs and the amount of renewable heat produced ${ }^{[15]}$.

\subsection{Initial Analysis after Implementation}

The administration and implementation of the $\mathrm{RHI}$ is designed to be straightforward, as anything overly complex is likely to go against the aim of incentivising the uptake of renewable heat. However, there are some issues that may cause confusion as the RHI scheme progresses. The RHI has been received well - as of March 2012, applications amounted to 300 - however only 15 of these had been approved and fully accredited, to allow payments to be made to the applicants (R. Gibson ${ }^{1}$ 2012, pers. comm., 20 March). With timescales of 4 weeks claimed for simple systems and 6 weeks for complex systems, for an $f 860$ million scheme the rate of accreditation should have been higher. One year on, applications rose to 1710 as of $28^{\text {th }}$ February 2013, with 603 installations fully accredited and having received a payment ${ }^{[16]}-a$ marked increase after an evidently slow start.

An initial performance review however highlights a slight misalignment of the process of obtaining permission and the accreditation for a renewable heat installation. For example,

\footnotetext{
${ }^{1}$ Ruth Gibson is Technical Development Manager ( $\mathrm{RHI}$ ) at Ofgem, and is involved with administration of the RHI.
} 
planning permission for certain technologies has to be sought before the $\mathrm{RHI}$ is applied for, and before the installation is accredited by Ofgem - but this process is extremely risky for the installation owner as there is no guarantee that their installation will be accredited even after the costly planning application is submitted (M. Drummond ${ }^{2} 2012$, pers. comm., 20 March).

Also, whilst pre-approval for technologies above 200kW exists, no pre-approval process exists for smaller projects - that is, smaller installations have to be in place before the $\mathrm{RHI}$ is applied for, and before the installation is accredited by Ofgem (M. Drummond 2012, pers. comm., 20 March). This could be seen as a huge risk for smaller project installers in terms of initial costs and no guarantee of receiving the accreditation required in order to receive the RHI payments.

March 2012 also saw DECC issue a consultation on interim cost control for the RHI which would suspend the scheme until the next financial year should the budget of $£ 860$ million be under threat through application numbers and accreditation rates ${ }^{[17]}$. At a critical point when the scheme was just initiated, this was an unusual move having the potential to make prospective applicants nervous.

It is evident that these issues may limit the RHI's effectiveness in incentivising the uptake of renewable heat for both small-scale and large-scale producers across the UK. From an environmental aspect, it is also notable that there is no minimum efficiency directive for installations within the $\mathrm{RHI}$, and there are no specific criteria for the calorific value of the fuel to be used (as, for example, in solid biomass facilities that generate heat) (R. Gibson 2012, pers. comm., 20 March).

\subsection{Domestic and Non-Domestic installations}

The distinction between domestic installations (which is open for applications as of spring 2014) and non-domestic installations is also not entirely clear within the administration framework of the RHI. Ofgem have stated that the RHI is currently open for applications from the nondomestic sector, however a critical element not fully explored or emphasised by Ofgem is that two or more private dwellings using heat from the one renewable heat facility is currently eligible for RHI payments (R. Gibson 2012, pers. comm., 20 March). This means that, even though households can currently receive one off payments under the Renewable Heat Premium Payment scheme (RHPP), administered by the Energy Saving Trust to assist in installing renewable heat technologies, many individual private properties may be missing out on the RHI as it currently stands. As the expected deployment date for the RHI scheme in the domestic sector is now spring 2014 after some delays, this is worth considering as multiple domestic installations could be operating, owners could be receiving payments, and movement could be being made towards meeting climate change targets. Given that the cost of installation for any given renewable heat technology can run into many thousands of pounds, with lengthy payback timescales, many community groups and co-operative organisations - that is, those most likely to benefit from renewable heat technologies but who lack the formal business arrangement may be missing out aswell.

Fundamentally, the definition of domestic and non-domestic as supplied by Ofgem is not clear, and may result in many individuals and groups not exploring the RHI until much later in 2014 when the domestic sector is expected to come into force.

\footnotetext{
${ }^{2}$ Morag Drummond is Senior Manager, Business Operations (RHI) at Ofgem, and is involved with administration of the RHI.
} 


\subsection{A School Geothermal Heat Case Study}

A project has arisen that is soon to make use of the benefits that the $\mathrm{RHI}$ offers, both in terms of environmental and monetary savings, whilst adopting a novel approach to renewable heat. Glasgow City Council, Scotland, is in the advanced stages of a programme to modernise strategic learning establishments, specifically primary, special education needs schools, and pre 5 establishments ${ }^{[18]}$. Part of this programme has seen the commencement in January 2012 of the refurbishment of a Victorian primary school in Glasgow's West End.

Dowanhill Primary School, built in 1894, has a prime location within the Glasgow West End community. Situated off Byres Road - a main thoroughfare for shoppers and residents and close to Glasgow University, the historic building commands much admiration for the Victorian architecture. As such, Glasgow City Council saw it necessary to modernise, not demolish, at a cost of $f 9$ million, whilst staying inline with their development policies ${ }^{[18]}$. The school will have 14 new classrooms spanning 5 floors, a new extension wing housing nursery facilities and generalpurpose areas, and will service a heat requirement of $400 \mathrm{~kW}$.

Ultimately, Glasgow City Councils aims are to create a multi-use, multi-purpose facility (including a nursery and community space) that considers social, economic, and environmental goals, whilst incorporating sustainable architecture and construction into the design and management of the build ${ }^{[18]}$. It is understood that planning constraints often inhibit the ability to expand into one's own space, so the school is designed with this flexibility in mind whereby modifications and extensions can be completed without adverse environmental and social effects ${ }^{[18]}$.

\subsection{Geothermal Heating and the RHI}

The renewable technology element of the project in Glasgow's West End considers a novel approach to renewable heat, not yet applied anywhere in the UK. Two $100 \mathrm{~m}$ test boreholes found the school grounds to be preferential to the use of ground source heat - groundwater was present within the bedrock and the thermal conductivity of the boreholes were $75 \%$ and $78 \%$ higher than anticipated for shale and sandstone ${ }^{[15]}$. Ground Source Heat Pumps (GSHPs), of reasonable capacity, would therefore be entirely viable. GSHPs connected to eighteen $110 \mathrm{~m}$ boreholes laid out in the surrounding car park and adjoining playground are to supply heat for the school in combination with a Combined Heat and Power (CHP) facility ${ }^{[15]}$. During times of extreme cold, the CHP is to be used to protect the boreholes by sending heat down them if this facility is needed. In displacing the original oil fired boilers, this tandem approach crucially protects the asset, as far as is reasonably practical, from rising energy costs in the future.

GSHPs do however require a relatively small electrical input for their operation. Grid electricity can be considered as poor thermal efficiency energy transfer into electrical energy at the power station, and using this generated electricity for running the GSHPs would not contribute to the lowest possible cost and lowest carbon emissions ${ }^{[15]}$. Generating onsite electricity, using gas fired CHP, is considered a viable option whereby running costs for the GSHPs and overall emissions are minimized, whilst taking advantage of the lower price for mains gas. Onsite biomass facilities were also considered, however space constraints and infrastructure issues made this unfeasible. GSHPs provide the viable mechanism to explore this build within the RHI. 


\subsection{The $\mathrm{RHI}$ in Practice}

The $\mathrm{RHI}$ is therefore set to form a large part of the school refurbishment project in demonstrating the cost effectiveness and environmental viability of the build. To further support the project, a series of fortnightly mechanical service meetings were arranged by the principal contractor and held on site for the duration of the build, bringing together team members involved in ventilation, sprinklers, heating, controls such as the Building Management System (BMS), as well as plumbing and overall mechanical and electrical matters. Issues and general progress are communicated and discussed between all team members present, ensuring swift work-arounds from problem to solution as and when they arise.

Whilst the mechanical workshops held onsite are successful in identifying problems and maintaining progress, it is revealing to see that the $\mathrm{RHI}$ does not fall neatly within the construction phase of the build. The calculations for determining what element of the heat produced is truly renewable are fairly straightforward, as gas fired CHP is not classed as 'renewable'. Ofgem advises that the quantity of heat placed back into the ground, to protect the boreholes, should simply be subtracted from the quantity of heat extracted from the ground, which ensures a minimisation of heat meters (R. Gibson 2012, pers. comm., 20 March) (fig. 1).

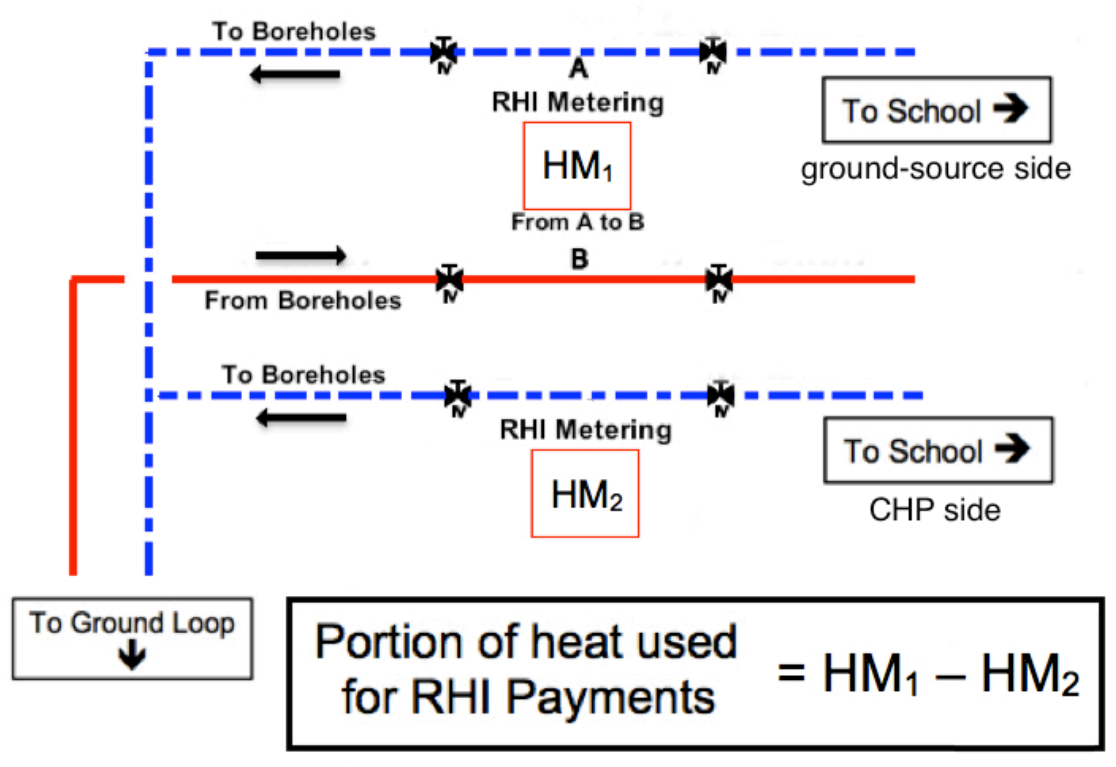

Fig. 1 Layout of RHI Meters

However, there exists uncertainty for the contractor as to where the heat meters are to be positioned and when the $\mathrm{RHI}$ accreditation will be achieved. This is compounded by there existing little to no framework for where the $\mathrm{RHI}$ fits within a build, yet it is this crucial incentive scheme that aims to make many projects viable. For this specific project, the RHI meters and metering were a consistent unknown. Quite simply, if the RHI is to succeed, it has to find a recognised and universally accepted place within planning guidelines. 


\subsection{Conclusions}

Examining the $\mathrm{RHI}$ framework and exploring the options for renewable heat through a real world project, it is apparent that the RHI scheme has some way to go if it is to incentivise the uptake of renewable heat towards meeting climate change targets. Effective implementation of the RHI scheme should take issues, such as planning and accreditation, into account before they cause a hindrance, as more installations come online ready for $\mathrm{RHI}$ accreditation. Implementation of renewable heat on a broader scale should also consider universal integration strategies to allow a wider uptake of renewable heat technologies.

Whilst the $\mathrm{RHI}$ is clear and transparent within a policy context, at a construction level phase there needs to be a significant improvement in how the $\mathrm{RHI}$ is managed and supported in order to fully aid implementation. This could be through more accessible guidance on the RHI for those working on construction sites, or alternatively a broader awareness on the importance of the RHI within an entire project. In many cases, the RHI is, and should be seen as, the crucial component that makes many projects viable.

In a broader sense, the $\mathrm{RHI}$ also represents an opportunity to transform the heating market across varying technologies, continual reduction of carbon emissions, and integrated control measures towards a resilient and secure 'future-proof' energy economy. This gives a significant advantage for those willing to innovate, such as in the geothermal refurbishment project in Glasgow. However, if the RHI is not integrated correctly, project success may be compromised, instead hindering the heating market and the technologies that are adopted.

For renewable heat to succeed, innovative projects are crucial to test feasibility and cost, revenue, and also the management of risk. Without pioneering examples, the move towards meeting EU Climate Change targets will be slow - however, for those willing to overcome what may be viewed as risks, significant benefits and valuable experience can be attained. Innovative projects such as that in Glasgow's West End are supported by the RHI, though the lack of clarity in how the RHI is integrated in the build, and how the RHI functions out with policy and in the real world, is not fully supporting the implementation of a scheme that has the potential to transform the heating market.

It could be that it is too early to comment on the RHI giving its lifetime of 20 years - however, when multi-million pound developments can either succeed or fail based on $\mathrm{RHI}$ support, issues such as those identified here are shown to be significant, and should be addressed for future renewable heating projects.

\section{References}

[1] European Commission, 2009. Directive 2009/28/EC of the European Parliament and of the Council of 23 April 2009 on the promotion of the use of energy from renewable sources. Office for Official Publications of the European Communities, Luxembourg.

[2] Climate Change Act (2008). London: HMSO.

[3] Christian Aid, et al., 2011. Climate Check: An Analysis of the Government's Delivery of its Low Carbon 
Commitments, [Online]. Available at: http://www.green-

alliance.org.uk/uploadedFiles/Publications/reports/Climate_check\%20report\%20September\%202011.pdf [Accessed 15th April 2012].

[4] European Commission, 2011. A Roadmap for Moving to a Competitive Low Carbon Economy in 2050, [Online]. Available at: http://eur-

lex.europa.eu/LexUriServ/LexUriServ.do?uri=COM:2011:0112:FIN:EN:PDF [Accessed 20th April 2012].

[5] Black, R., 2011. BBC News: UK 'Set to Miss' Climate Targets, [Online]. Available at:

http://www.bbc.co.uk/news/science-environment-14949188 [Accessed 20th April 2012].

[6] DECC, 2012. The Future of Heating: A Strategic Framework for Low Carbon Heat in the UK, [Online]. Available at: http://www.decc.gov.uk/assets/decc/11/meeting-energy-demand/heat/4805-futureheating-strategic-framework.pdf [Accessed 27th April 2012]

[7] Energy Savings Trust, 2012. Feed-In Tarrifs Scheme (FITs), [Online]. Available at: http://www.energysavingtrust.org.uk/Generating-energy/Getting-money-back/Feed-In-Tariffs-schemeFITs [Accessed 18th April 2012].

[8] DECC, 2012. Community Energy Saving Programme (CESP), [Online]. Available at: http://www.decc.gov.uk/en/content/cms/funding/funding_ops/cesp/cesp.aspx [Accessed 27th April 2012]

[9] Ownergy Plc, 2012. Renewable Heat Incentive, [Online]. Available at: http://www.rhincentive.co.uk/RHI/ [Accessed 27 ${ }^{\text {th }}$ April 2012]

[10] DECC, 2012. Energy Act 2008, [Online]. Available at:

http://www.decc.gov.uk/en/content/cms/legislation/energy_act_08/energy_act_08.aspx [Accessed $25^{\text {th }}$ April 2012]

[11] Ofgem, 2012. Renewable Heat Incentive, [Online]. Available at: http://www.ofgem.gov.uk/eserve/RHI/Pages/RHI.aspx [Accessed $25^{\text {th }}$ April 2012]

[12] DECC, 2011. Renewable Heat Incentive Impact Assessment, [Online]. Available at: http://www.decc.gov.uk/assets/decc/11/meeting-energy-demand/renewable-energy/3775-renewableheat-incentive-impact-assessment-dec-20.pdf [Accessed $18^{\text {th }}$ April 2012]

[13] DECC, 2011. Renewable Heat Incentive Scheme - Q \& A Index. Cited in Abu-Bakar et. al., 2013. Is Renewable Heat Incentive the Future? Renewable and Sustainable Energy Reviews, [Online]. 26 (2013), pp. 365-378. Available at: http://www.sciencedirect.com/science/article/pii/S136403211300347X [Accessed 26th Jan 2014].

[14] Abu-Bakar et. al., 2013. Is Renewable Heat Incentive the Future? Renewable and Sustainable Energy Reviews, [Online]. 26 (2013), pp. 365-378. Available at:

http://www.sciencedirect.com/science/article/pii/S136403211300347X [Accessed 26th Jan 2014].

[15] Glasgow City Council, 2010. Notre Dame and St Peters Low and Zero Carbon Renewables Feasibility Report. Glasgow: Glasgow City Council.

[16] DECC, 2013. Renewable Heat Incentive and Renewable Heat Premium Payments Quarterly Statistics, [Online]. Available at:

https://www.gov.uk/government/uploads/system/uploads/attachment_data/file/153584/rhi_rhpp_depl oyment_data_march_2013.pdf [Accessed $1^{\text {st }}$ April 2013] 
[17] Williamson, K., 2012. Renewable Energy Focus: UK Renewable Heat Incentive faces 'Cost Control' after 4 months, [Online]. Available at: http://www.renewableenergyfocus.com/view/24808/uk-renewableheat-incentive-faces-cost-control-after-4-months/ [Accessed 20 ${ }^{\text {th }}$ April 2012]

[18] Glasgow City Council, 2010. Notre Dame and St Peters Brief. Glasgow: Glasgow City Council. 